\title{
Status of Oral Care according to the Type of Surgery for Inpatients at Dental Hospitals
}

\author{
Jae-Eun Kim', Young-Jae Yoon ${ }^{2}$, Yong-Dae Kwon², and Sang-Hwan $\mathrm{Oh}^{3, \dagger}$ \\ ${ }^{1}$ Department of Dentistry, Graduate School, Kyung Hee University, Seoul 02447, ${ }^{2}$ Department of Oral \& \\ Maxillofacial Surgery, School of Dentistry, Kyung Hee University, Seoul 02447, ${ }^{3}$ Department of Dental Hygiene, \\ College of Medical Science, Konyang University, Daejeon 35365, Korea
}

\begin{abstract}
Background: The aim of this study was to understand the importance of professional oral care for inpatients by examining the type and frequency of surgery and hospital discharge period at dental hospitals, and identify the types of professional oral care actually in progress.

Methods: In this study, the type of surgery and length of hospitalization were investigated among patients admitted to the dental hospital for oral and maxillofacial surgery, and the professional oral care status of inpatients who had difficulty self-managing their oral care was retrospectively identified by collecting data on oral care before and after surgery, including the type and frequency. Results: The majority of inpatients at dental hospitals were male $(57.6 \%)$, elderly patients over 60 years accounted for $20 \%$ of patients, and the average length of hospitalization was 4 days. In the 20 s (aged $20 \sim 29 \mathrm{y}$ ), the number of orthognathic surgery patients (73.1\%) was high, and the incidence of cysts was high in middle-aged patients. Regarding the oral care of hospitalized patients, scaling was performed once by a dentist before surgery. After surgery, surgical dressings using $\mathrm{H}_{2} \mathrm{O}_{2}$ balls were applied and oral care education was introduced before discharge.

Conclusion: Based on the results of this study, professional oral care is essential to prevent infection and complications caused by oral bacteria among inpatients at dental hospitals. It is necessary to use various oral hygiene aids for inpatients and to conduct effective oral care instruction according to each patient's situation. In addition, it is necessary to raise awareness and the role of dental hygienists in professional oral care.
\end{abstract}

Key Words: Dental hygienist, Inpatients, Oral and maxillofacial surgery, Oral care

\section{Introduction}

As modern society is industrialized due to continued economic growth, the number of trauma patients is increasing due to various types of accidents, including traffic accidents ${ }^{1)}$. With the improvement of socioeconomic status and the development of medical technology, the elderly population is rapidly increasing, and aesthetic plastic surgery has become prominent among young people ${ }^{2,3)}$. Trauma patients, elderly patients, and plastic surgery patients are accompanied by general anesthesia, especially trauma, requiring complex treatment; elderly patients often require inpatient treatment because they have systemic diseases such as high blood pressure, diabetes, and cardiovascular disease ${ }^{4)}$. This increase in the number of inpatients suggests a need for comprehensive oral health management, including general health. Oral health and general health are closely related, so during long-term inpatient treatment, it is difficult to maintain oral health ${ }^{5,6)}$. Go et al. ${ }^{7)}$ reported that professional oral care and education are essential for long-term care hospital inpatients who have difficulty in self-care. $\mathrm{Noh}^{8)}$ emphasized the importance of oral care and education during hospitalization, reporting that inpatients had insufficient oral care and did 
not use oral hygiene aids properly. Oral care is the most basic and important activity for maintaining oral health ${ }^{9)}$. However, in the case of hospitalized patients, oral care, such as toothbrushing, which must be continuously performed, is neglected because of the inconvenience caused by surgery ${ }^{10}$. In particular, inpatients at dental hospitals performing internal/external surgery have difficulties in oral care activities due to complications or pain after surgery. Oral care is one of the most important factors determining the prognosis of surgery; therefore, thorough oral care is more important for inpatients in dental hospitals. Until now, studies on oral health targeting inpatients at dental hospitals are scarce, and there are few studies on the actual condition of oral care.

Therefore, this study aimed to suggest recommendations for dentists and dental hygienists by identifying the oral care conditions of inpatients in dental hospitals and evaluating the need for a specialized oral care system for inpatients.

\section{Materials and Methods}

\section{Research subjects}

This study was conducted in patients who underwent surgery under general anesthesia at the Department of Oral and Maxillofacial Surgery at Kyung Hee University Dental Hospital for a total of 2 years and 6 months from January 2018 to June 2020. Among them, data of 1,402 inpatients were finally investigated, except for cases in which records of dates were unclear or the disease classification code was incorrect. The types of surgery and the actual conditions related to oral care were investigated among inpatients at dental hospitals before and after surgery. Among them, we identified professional oral care cases in which a dentist or dental hygienist directly performed procedures, such as removal of bacteria and debris in the oral cavity, and management of dental plaque and calculus, in patients who had difficulty managing their own oral hygiene during hospitalization. The selected subjects consisted of various age groups, from teenagers to patients in their 80 s.

This study is a retrospective study that analyzes already recorded clinical data, and confidentiality measures were taken to protect patient information during the data collection process. Consent was exempted because it was judged that there was very little potential for negative harm or human rights violations to the patient.

\section{Study methods}

This investigation was conducted as a retrospective study comparing past medical records on oral care of inpatients, and medical records were collected through the electronic medical record system of the hospital. The average period of hospitalization was identified, and the oral care status of inpatients who had difficulty managing their own oral care by themselves was identified by collecting data on oral care before and after surgery, including the type and frequency.

\section{Data analysis}

The data collected in this study summarized the general characteristics of the subjects based on the mean and standard deviation. Using chi-square analysis, the relationship between the surgical frequency for each disease according to sex and age was investigated. Statistical tests were performed using the SPSS software (ver. 25.0; IBM Corp., Armonk, NY, USA). Statistical significance was set at a p-value less than 0.05 .

Table 1. Demographics of Inpatients

\begin{tabular}{cc}
\hline \multicolumn{1}{c}{ Variable } & Value \\
\hline Sex & \\
Male & $808(57.6)$ \\
Female & $594(42.4)$ \\
Age ${ }^{\mathrm{a}}(\mathrm{y})$ & $38.34 \pm 21.01$ \\
$10 \mathrm{~s}$ & $263(18.8)$ \\
$20 \mathrm{~s}$ & $383(27.3)$ \\
$30 \mathrm{~s}$ & $144(10.3)$ \\
$40 \mathrm{~s}$ & $159(11.3)$ \\
$50 \mathrm{~s}$ & $173(12.3)$ \\
$60 \mathrm{~s}$ & $145(10.3)$ \\
$70 \mathrm{~s}$ & $94(6.7)$ \\
$80 \mathrm{~s}$ & $39(2.8)$ \\
$90 \mathrm{~s}$ & $2(0.1)$ \\
Period of inpatients (day) & $4.06 \pm 4.52$ \\
\hline
\end{tabular}

Values are presented as number (\%) or mean \pm standard deviation. ${ }^{a}$ Age was classified into $10 \mathrm{~s}(10 \sim 19 \mathrm{y}), 20 \mathrm{~s}(20 \sim 29 \mathrm{y})$, etc. 


\section{Results}

\section{Demographics of inpatients}

Among inpatients, the proportion of males was high $(57.6 \%)$, and the age range ranged from 4 to 94 years. The proportion of elderly patients aged $>60$ years accounted for $20 \%$ of the study sample. The average hospitalization period was relatively short (4 days), and in some cases, long-term hospitalization was up to 44 days (Table 1).

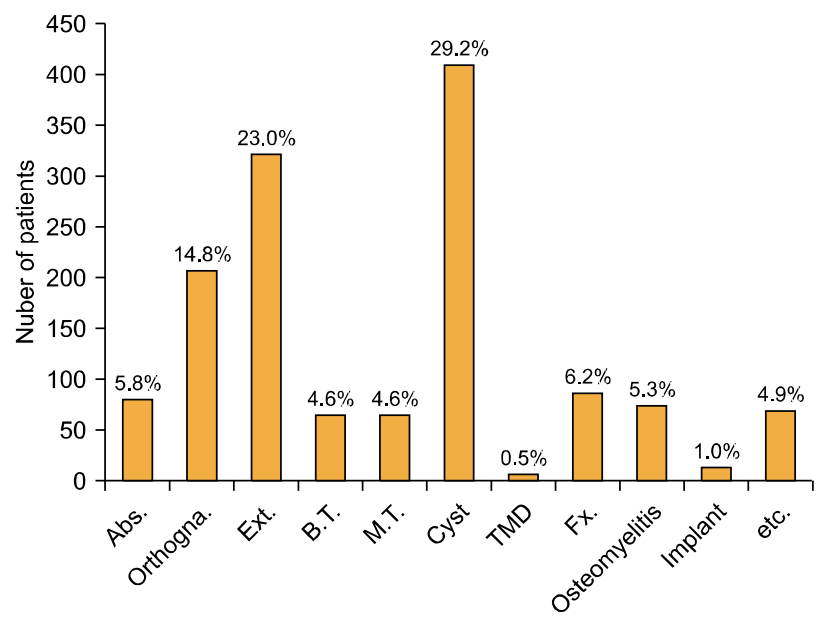

Fig. 1. Classification of surgery and disease. Abs.: abscess, Orthogna.: orthognathic surgery, Ext. : tooth extraction, B.T. benign tumor, M.T. : malignant tumor, Fx. : fracture, TMD: temporomandibular disorder.

\section{Type and frequency of surgery among inpatients}

After subdividing and categorizing surgeries for inpatients at dental hospitals by type, such as abscess (Abs.), orthognathic surgery (Orthogna.), tooth extraction (Ext.), benign tumor, cyst, temporomandibular disorder (TMD), fracture (Fx.), osteomyelitis, and implant, the frequency of cyst-related surgery was the highest (29.2\%), and Ext. (23.0\%), Orthonga. (14.8\%), and Fx. (6.2\%) accounted for the highest frequency (Fig. 1). Most of the patients' hospitalization motives and chief complaints were discomfort and pain in the oral cavity. Teenagers accounted for the largest proportion of Ext. (45.0\%), and those in their twenties had the highest frequency of Orthogna. (73.1\%). Cysts were most common among patients in their $30 \mathrm{~s}$ to $60 \mathrm{~s}$, and from the age of 70 years, osteomyelitis due to bone function decline caused by osteoporosis, and chronic and complex diseases frequently appeared. In addition, the cysts and Fx. were frequently found in male, and Ext. and Orthogna. were significantly more common in those under 40 years of age. After the age of 40 years, the frequency of cysts and benign tumors was high (Table 2).

Table 2. Types of Surgery according to Sex and Age

\begin{tabular}{|c|c|c|c|c|}
\hline \multirow{2}{*}{ Type of surgery } & \multicolumn{2}{|c|}{ Sex } & \multicolumn{2}{|c|}{$\operatorname{Age}^{a}(y)$} \\
\hline & Male & Female & $\leq 39$ & $\geq 40$ \\
\hline Cyst & $276(67.3)$ & $134(32.7)$ & $197(48.0)$ & $213(52.0)$ \\
\hline Ext. & $185(57.5)$ & $137(42.5)$ & 267 (82.9) & $55(17.1)$ \\
\hline Orthogna. & $113(54.3)$ & $95(45.7)$ & $199(95.7)$ & $9(4.3)$ \\
\hline Fx. & $68(78.2)$ & $19(21.8)$ & $45(51.7)$ & $42(48.3)$ \\
\hline Abs. & $34(42.0)$ & $47(58.0)$ & $12(14.8)$ & $69(85.2)$ \\
\hline Benign tumor & $27(41.5)$ & $38(58.5)$ & $32(49.2)$ & $33(50.8)$ \\
\hline Malignant tumor & $42(64.6)$ & $23(35.4)$ & $6(9.2)$ & $59(90.8)$ \\
\hline Osteomyelitis & $19(25.7)$ & $55(74.3)$ & $1(1.4)$ & $73(98.6)$ \\
\hline Implant & $8(57.1)$ & $6(42.9)$ & $2(14.3)$ & $12(85.7)$ \\
\hline TMD & $3(42.9)$ & $4(57.1)$ & $1(14.3)$ & $6(85.7)$ \\
\hline$\chi^{2}$ & \multicolumn{2}{|c|}{82.319} & \multicolumn{2}{|c|}{465.324} \\
\hline p-value & \multicolumn{2}{|c|}{$<0.001$} & \multicolumn{2}{|c|}{$<0.001$} \\
\hline
\end{tabular}

Values are presented as number $(\%)$.

Ext.: tooth extraction, Orthogna.: orthognathic surgery, Fx.: fracture, Abs.: abscess, TMD: temporomandibular disorder.

${ }^{\mathrm{a}}$ The criterion for age classification is the average value.

This table was analyzed by Monte carlo methods. 


\section{Status of oral care for inpatients}

In the case of professional oral care for inpatients, scaling by a dentist was usually performed once the day before surgery, and examination and detailed checks were performed to understand the patient's overall condition and oral health status. However, in cases where the patient's cooperation is very weak, there is limited mouth opening due to a severe Fx., or in severe malignant tumors, preoperative scaling is considered, and a simple oral dressing uses $\mathrm{H}_{2} \mathrm{O}_{2}$ balls as an alternative. After surgery, it becomes more difficult for the patient to manage the oral cavity directly; therefore, every morning during the hospitalization period, a dressing is performed to remove and disinfect foreign substances and residues in the oral cavity through suction. As the discharge date approached, oral care instruction was conducted in a way that explained precautions related to surgery and oral care before discharge. Oral care education items included correct brushing, use of an interdental brush, and use of dental floss. All professional oral care and education for inpatients was mainly performed by dentists (Table 3 ).

\section{Discussion}

During inpatient treatment, there is a high possibility that oral health problems may appear, as oral care activities may be neglected because of various factors such as pain or movement discomfort due to surgery ${ }^{11)}$. In this respect, understanding the oral care status of inpatients is meaningful in terms of oral health promotion. In particular, it has a more important value for inpatients in dental hospitals who require better oral care. Therefore, this study attempted to present recommendations for dentists and dental hygienists by retrospectively investigating the oral care status of inpatients and evaluating the necessity of a professional oral care system for inpatients. This study investigated the status of professional oral care in relation to the type of surgery in 1,402 patients admitted to

Table 3. Professional Oral Care according to the Type of Surgery

\begin{tabular}{|c|c|c|}
\hline \multicolumn{2}{|c|}{ Type of Surgery } & \multirow{2}{*}{$\begin{array}{l}\text { Professional oral care methods (professional) } \\
\text { Perform } 1 \text { full-mouth scaling on the day before surgery (dentist) }\end{array}$} \\
\hline Cyst & Before & \\
\hline & After & $\begin{array}{l}\text { For bacterial blocking, dressing the surgical site and surrounding mucous membranes using } \mathrm{H}_{2} \mathrm{O}_{2} \\
\text { balls every morning during hospitalization (dentist) }\end{array}$ \\
\hline \multirow[t]{2}{*}{ Ext. } & Before & Perform 1 full-mouth scaling on the day before surgery (dentist) \\
\hline & After & $\begin{array}{l}\text { For bacterial blocking, dressing the surgical site and surrounding mucous membranes using } \mathrm{H}_{2} \mathrm{O}_{2} \\
\text { balls every morning during hospitalization (dentist) }\end{array}$ \\
\hline \multirow[t]{2}{*}{ Orthogna. } & Before & Perform 1 full-mouth scaling on the day before surgery (dentist) \\
\hline & After & $\begin{array}{l}\text { After checking the residue in the mouth, remove it with suction every morning during } \\
\text { hospitalization (dentist) }\end{array}$ \\
\hline \multirow[t]{2}{*}{ Fx. } & Before & $\begin{array}{l}\text { Wipe the mucous membrane and teeth in the oral cavity using } \mathrm{H}_{2} \mathrm{O}_{2} \text { Ball just before surgery } \\
\text { (dentist) }\end{array}$ \\
\hline & After & $\begin{array}{l}\text { After checking the residue in the mouth, remove it with suction every morning during } \\
\text { hospitalization (dentist) }\end{array}$ \\
\hline \multirow[t]{2}{*}{ Abs. } & Before & Perform 1 full-mouth scaling on the day before surgery (dentist) \\
\hline & After & $\begin{array}{l}\text { For bacterial blocking, dressing the surgical site and surrounding mucous membranes using } \mathrm{H}_{2} \mathrm{O}_{2} \\
\text { balls every morning during hospitalization (dentist) }\end{array}$ \\
\hline \multirow[t]{2}{*}{ Osteomyelitis } & Before & Perform 1 full-mouth scaling on the day before surgery (dentist) \\
\hline & After & $\begin{array}{l}\text { For bacterial blocking, dressing the surgical site and surrounding mucous membranes using } \mathrm{H}_{2} \mathrm{O}_{2} \\
\text { balls every morning during hospitalization (dentist) }\end{array}$ \\
\hline \multirow[t]{2}{*}{ Except $^{\mathrm{a}}$} & Before & Reduction of oral bacteria by using $\mathrm{H}_{2} \mathrm{O}_{2}$ ball and saline just before surgery (dentist) \\
\hline & After & $\begin{array}{l}\text { Clean the oral mucosa and teeth using a } \mathrm{H}_{2} \mathrm{O}_{2} \text { ball and sterile gauze every morning during } \\
\text { hospitalization (dentist) }\end{array}$ \\
\hline
\end{tabular}

Ext.: tooth extraction, Orthogna.: orthognathic surgery, Fx.: fracture, Abs.: abscess.

${ }^{a}$ Except includes cases where cooperation is poor or it is difficult to open your mouth on their own.

Oral care education is provided when all are discharged.

Oral care education includes how to brush teeth and how to use an interdental toothbrush. 
dental hospitals. Most surgeries performed in dental hospitals were related to cysts, Ext., and Orthogna., and cysts were particularly frequent among middle-aged and elderly patients. The frequency of Orthogna. was higher in the younger generation, which we attribute to the tendency to devote increased interest to one's appearance as part of a full-fledged social life beginning in the $20 \mathrm{~s}^{12}$. Inpatients aged 60 years or older accounted for $20.8 \%$ of the study population, and there were long-term inpatients for more than one month. Considering that the proportion of the elderly population is continuously increasing, oral care for elderly inpatients is also important. A decrease in oral function due to aging can delay wound healing and increase the risk of infection ${ }^{13)}$. In addition, long-term hospitalization may be a risk factor for the development of periodontal disease due to the prolonged neglect of oral hygiene, and the bacterial growth rate in the oral cavity may be higher due to dry mouth, a common side effect of treatment drugs. The reality is that oral care for inpatients is difficult. In fact, there are difficulties in cooperation in the treatment of children and patients with disabilities, and there have been cases where oral care was difficult because of limited opening due to Fx. and Orthogna. ${ }^{14)}$. Therefore, it is necessary to develop an appropriate oral care method individualized for each patient. Oral bacteria act as an infection-causing factor during oral surgical operations, and complications from this can lead to more serious conditions ${ }^{15)}$. To prevent complications after surgery, the infection source must be removed. Since oral care becomes more difficult after surgery, the importance of professional oral care during hospitalization is further emphasized. According to the results of this study, only scaling was performed before surgery, and surgical dressing and oral care education were performed after surgery. Oral care education deals only with the use of representative oral hygiene aids such as toothbrushes, interdental brushes, and dental floss, which are limited to teeth. However, it has been reported that the bacterial growth rate is high in oral tissues surrounding the teeth ${ }^{16}$. Therefore, education on the use of oral hygiene aids, such as sponge brushes, can help manage various oral tissues such as the tongue, vestibule, and teeth. It is necessary to develop and popularize various oral hygiene products that can more effectively manage oral bacteria. In addition, for the oral care of inpatients, it is necessary to recognize the importance of oral care by conducting oral care instruction for patients, guardians, and ward personnel. In this study, dentists were responsible for oral care among inpatients. In actual clinical practice, the work of dental hygienists is often limited to medical assistance and tooth brush instruction, and in tertiary hospitals, interns and resident doctors mostly provide medical assistance. As with the scope of practice among dental hygienists who support oral health education and preventive dental treatment, dental hygienists need to support more professional and continuous oral care for inpatients who require it. Oral care education not only increases knowledge of oral hygiene, but also increases the frequency of brushing and oral hygiene aids, so the role of the dental hygienist in oral health education is very important. Additionally, Carey et al. ${ }^{17)}$ emphasized the importance of postoperative balanced nutrition. This affected not only oral health but also overall health. Within the scope of professional oral care, it is necessary to consider patient satisfaction, nutrition, and quality of life, rather than simply focusing on the limited scope of oral treatment.

As a limitation of this study, cases where the records of hospitalization and discharge dates were unclear or the disease classification code was incorrect were excluded from the analysis. In addition, it is difficult to generalize the results of the study because inpatients were arbitrarily designated at dental hospitals. To overcome this limitation, it is necessary to increase the number of study subjects, select a control group and an experimental group, perform expert oral care for a certain period, and evaluate the magnitude of the effect on oral health by comparing the groups over time. Despite these limitations, this study measured the oral care of inpatients in dental hospitals, and it is expected to be used as basic data for effective oral health promotion plans for professional oral care of inpatients in the future.

Oral care for inpatients was performed within a limited range. Most exams are performed to check the condition before and after surgery and to prepare for surgery, rather than provide professional oral care. The therapeutic aspect of the surgery itself is important, but among surgical 
procedures performed in the oral cavity, oral care is essential to prevent secondary infection in the oral cavity. The need for continuous oral health status checks and management should be emphasized for inpatients with poor oral care. For effective oral care among inpatients, measures such as the promotion of preventive specialists, including dental hygienists and oral care educators, are considered.

\section{Notes}

\section{Conflict of interest}

No potential conflict of interest relevant to this article was reported.

\section{Ethical approval}

This study was approved by the Institutional Review Board of Kyung Hee University Dental Hospital (approval number: KH-DT21033).

\section{Author contributions}

Conceptualization: Sang-Hwan Oh and Jae-Eun Kim. Data acquisition: Jae-Eun Kim and Young-Jae Yoon. Visualization: Yong-Dae Kwon. Supervision: Yong-Dae Kwon. Writing-original draft: Jae-Eun Kim and Young-Jae Yoon. Writing-review \& editing: Sang-Hwan Oh and Yong-Dae Kwon.

\section{ORCID}

Jae-Eun Kim, https://orcid.org/0000-0003-2586-6604

Young-Jae Yoon, https://orcid.org/0000-0002-2325-2484

Yong-Dae Kwon, https://orcid.org/0000-0001-9620-4814

Sang-Hwan Oh, https://orcid.org/0000-0002-5944-0129

\section{References}

1. Kim JJ, Suh GJ, Jeong KY, et al.: Management of severe trauma patients in the emergency intensive care unit. $J$ Korean Soc Traumatol 24: 98-104, 2011.

2. Jang KA, Kim GE, Heo SE: The effect of professional oral care by time point on oral health status of inpatients in a nursing hospital. J Korean Soc Oral Health Sci 7: 92-97, 2019 . https://doi.org/10.33615/jkohs.2019.7.3.92

3. Satoh K, Mitsukawa N: Mandibular marginal contouring in oriental aesthetic surgery: refined surgical concept and operative procedure. Ann Plast Surg 72: 498-502, 2014. https://doi.org/10.1097/SAP.0b013e31826a18d3

4. Jeon JH, Kwon JA, Nam JM, Park HB, Song YJ, Choi JS: Comparison of oral health related characteristics between a long-term patients and general population. J Korean Soc Dent Hyg 16: 11-18, 2016. https://doi.org/10.13065/jksdh.2016.16.01.11

5. Heo SE: A convergence study on the effect of subjective systemic health status and health behavior on oral healthrelated quality of life. J Korea Converg Soc 9: 135-142, 2018. https://doi.org/10.15207/JKCS.2018.9.9.135

6. Lee JH, Hwang TY: Oral health status and care needs of elderly patients in long-term care hospital. J Korean Soc Dent Hyg 15: 411-416, 2015. https://doi.org/10.13065/jksdh.2015.15.03.411

7. Go HB, Kim MG, Kim JY, et al.: The relationship between dementia and oral health in some elderly in Daejeon. J Dent Hyg Sci 16: 481-487, 2016. https://doi.org/10.17135/jdhs.2016.16.6.481

8. Noh EM: A study of hospitalized patients' knowledge and practice of oral health. J Korean Soc Dent Hyg 7: 247-258, 2007.

9. Choi MS, Kim DK: Reviews of literature on dental plaque control and oral hygiene education in Korea. J Dent Hyg Sci 17: 87-98, 2017. https://doi.org/10.17135/jdhs.2017.17.2.87

10. Choi SM, Kim GU, Sakong J: Effects of professional oral care for long-term patients in nursing facilities on the Streptococcus mutans population in the intraoral region. $\mathrm{J}$ Korea Acad-Ind Cooper Soc 15: 5062-5069, 2014. https://doi.org/10.5762/KAIS.2014.15.8.5062

11. Ahn KS, Ji MG, Min HH: A study on dental professionals' recognition on a system of long-term care insurance for the elderly. J Korean Acad Dent Hyg Educ 9: 169-180, 2009.

12. Kim JS: Experiences in appearance management with esthetic treatment of female college students. J Korean Public Health Nurs 28: 359-371, 2014. https://doi.org/10.5932/JKPHN.2014.28.2.359

13. Ettinger RL: Oral health and the aging population. J Am Dent Assoc 138 Suppl: 5S-6S, 2007. 
https://doi.org/10.14219/jada.archive.2007.0357

14. Seo KS, Shin TJ, Kim HJ, et al.: Clinico-statistical analysis of cooperation and anesthetic induction method of dental patients with special needs. J Korean Dent Soc Anesthesiol 9: 9-16, 2009.

15. Lee JI, Kwon M, Roh JL, et al.: Postoperative hypoalbuminemia as a risk factor for surgical site infection after oral cancer surgery. Oral Dis 21: 178-184, 2015.

https://doi.org/10.1111/odi.12232
16. Aas JA, Paster BJ, Stokes LN, Olsen I, Dewhirst FE: Defining the normal bacterial flora of the oral cavity. J Clin Microbiol 43: 5721-5732, 2005.

https://doi.org/10.1128/JCM.43.11.5721-5732.2005

17. Carey S, Ferrie S, Young J, Allman-Farinelli M: Long-term nutrition support in gastrointestinal disease- a systematic review of the evidence. Nutrition 28: 4-8, 2012. https://doi.org/10.1016/j.nut.2011.07.004 